\title{
Salish Kootenai College and U.S. Geological Survey Partnership_Enhancing Student Opportunities and Professional Development
}

\section{Salish Kootenai College}

Salish Kootenai College (SKC), in the Flathead Reservation in the northwestern corner of Montana, is the largest of the seven Tribal colleges in the State. Formally established in 1977, SKC is a leader in Tribal education, being the only Tribal college in the United States that offers a 4-year Bachelor of Science in hydrology, forestry, and wildlife biology. Curricula at SKC also include a certificate in geospatial studies, which includes classes in remote sensing and advanced geographic information systems (GIS).

\section{U.S. Geological Survey Workshops}

In 2011, U.S. Geological Survey (USGS) National Tribal Liaison Monique Fordham (Office of Tribal Relations, Office of Science Quality and Integrity) began discussions with SKC faculty to examine ways the USGS could assist with classes taught as part of the new hydrology program at the college. With funding provided by the USGS Office of Tribal Relations (OTR), USGS scientists from the Wyoming-Montana Water Science Center (WY-MT WSC) began collaborating with SKC,

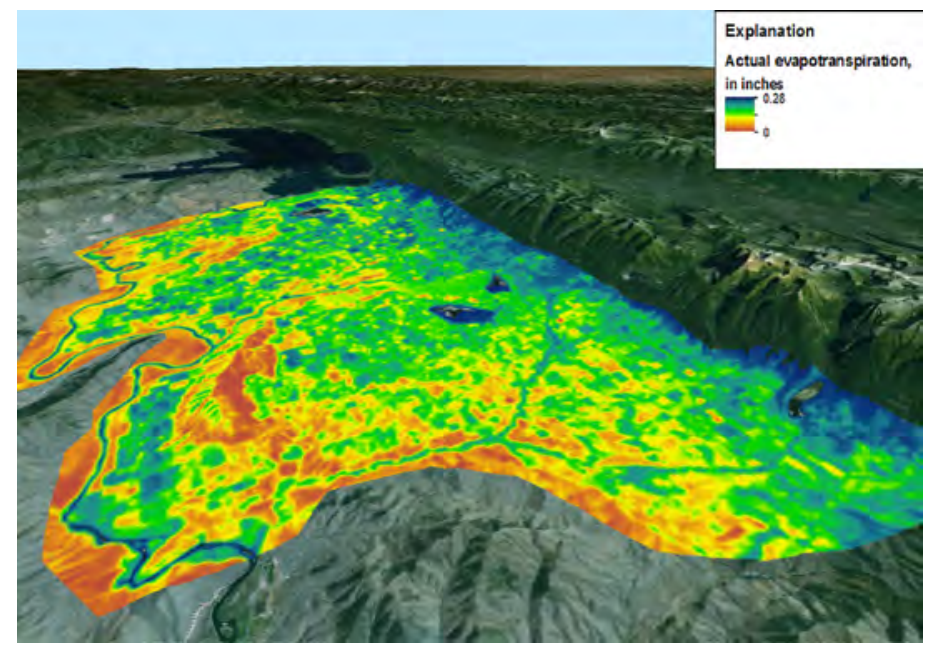

During the workshop taught in May 2013, students used Landsat 5 satellite imagery to estimate actual evapotranspiration from agricultural land near Flathead Lake, Montana. Datasets like this can be used to determine potential areas of stressed vegetation, an important environmental topic in the Flathead Reservation.

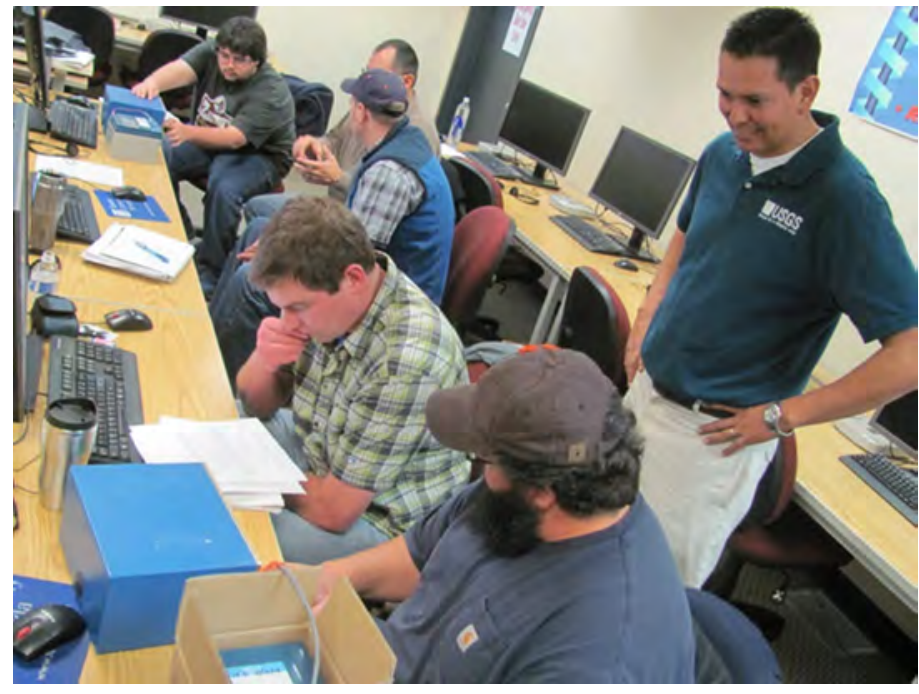

Aroscott Whiteman, U.S. Geological Survey hydrologist and instructor at one of the workshops, provided first-hand knowledge about the collection and analysis of hydrologic data.

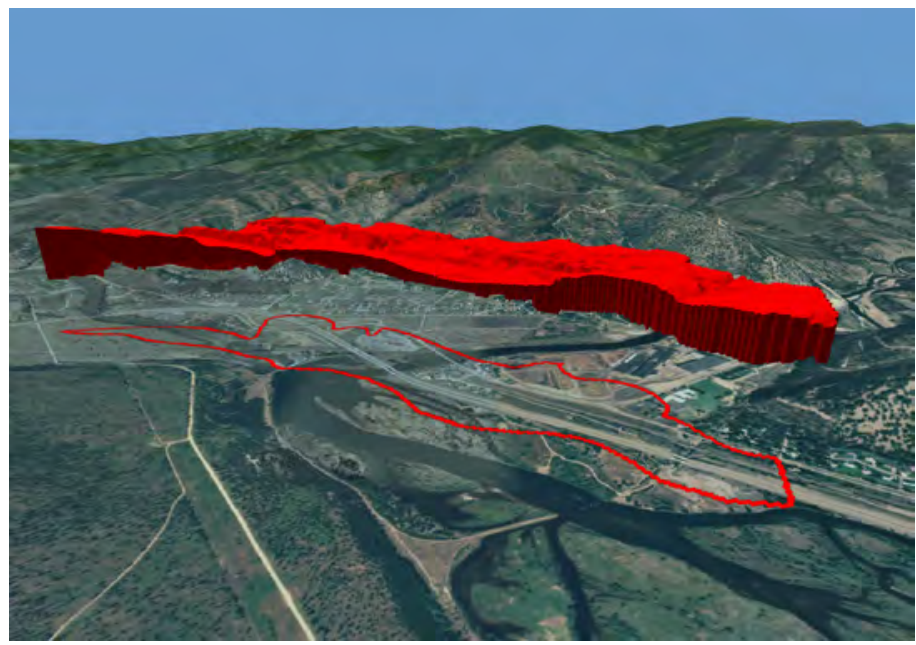

During the workshop taught in December 2014, students created a three-dimensional representation of contaminated groundwater near Milltown, Montana. This was a practical example of how the students might guide future water-resources development and remediation. 
and, in 2012, Roy Sando developed and taught two geospatial workshops. All workshops are designed to provide real-world solutions to assist with understanding environmental topics of importance on and around the Flathead Reservation. With additional funding from OTR, Roy Sando, Aroscott Whiteman, and Charlie Besteder have developed and taught six additional workshops in the past five academic years: four geospatial workshops, which have been incorporated into the SKC geospatial certificate curriculum, and two hydrologic workshops.

Topics of the workshops have included classifying land cover using remote sensing, characterizing stream channel migration, estimating actual evapotranspiration, modeling groundwater contamination plumes, and building custom GIS tools. Class size is generally about 15 students to ensure each student has adequate one-on-one time with the instructors.

The workshops have enhanced the educational experience of SKC students and the Confederated Salish and Kootenai Tribal Community. "Working with the USGS allows SKC to diversify hands-on learning experiences for students and the Tribal Community using local, Tribally relevant, realworld examples - this partnership has really been among the most fruitful I've taken part in," noted Robert Kenning, SKC Professor of Forestry. Likewise, USGS scientists have also benefited by learning more about SKC, the Tribal Community, and environmental topics of importance on the Flathead Reservation.

\section{Benefits of the Partnership-Beyond the Classroom}

By contributing to the educational training of SKC students and establishing this high level of collaboration with a Tribal college, the USGS is demonstrating its commitment to helping build the next generation of Tribal scientists. These graduates may go on to science careers with the Confederated Salish and Kootenai Tribes, other Native Nations, or with Federal, State, or private entities.

This "proof of concept" has been successful, and the WY-MT WSC hopes to continue this new and positive relation with SKC and the Tribal Community. The USGS project lead

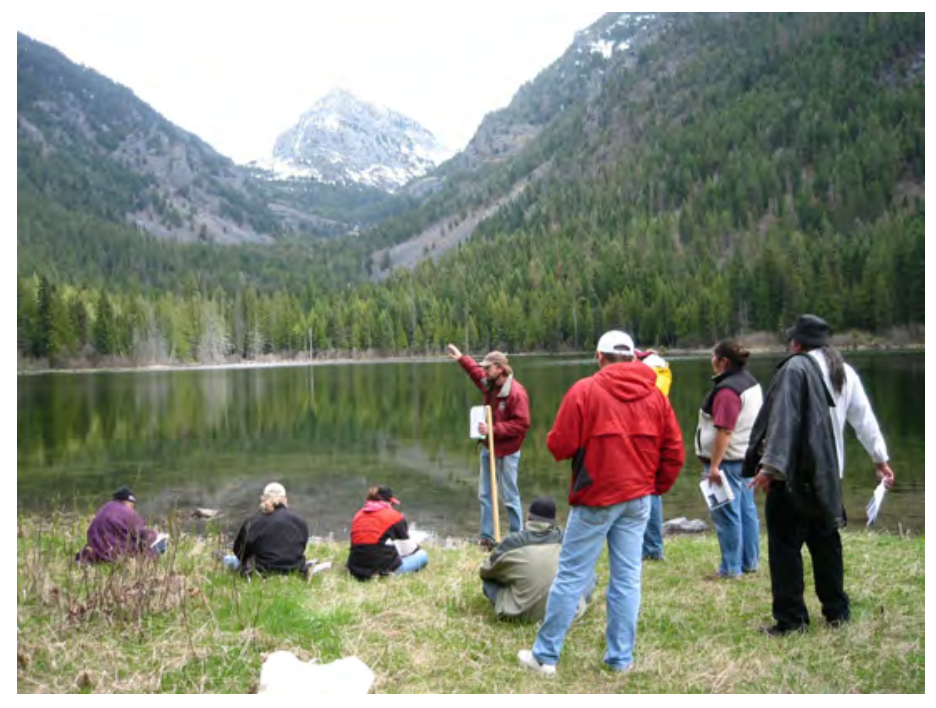

Salish Kootenai College professor Adrian Leighton talking about ecology to students on a field trip at Swartz Lake on the Flathead Reservation. Photograph courtesy of Robert Kenning, Salish Kootenai College.

Sando adds, "We hope to keep this great effort going. The benefits to SKC, the Tribal Community, and the USGS are clearly evident in such a short amount of time. We've learned so much about SKC and the amazing potential the students have to affect positive change in their communities."

\section{By Roy Sando and Monique Fordham}

\section{For more information, contact:}

Director, Wyoming-Montana Water Science Center

U.S. Geological Survey

3162 Bozeman Avenue

Helena, MT 59601

(406) 457-5900

dc_mt@usgs.gov 